\title{
Nestin, an important marker for differentiating oligodendroglioma from astrocytic tumors
}

\begin{abstract}
Background: Nestin is an acronym for neuroepithelial stem cell protein. It is an intermediate filament protein expressed in proliferating cells during the developmental stages in a variety of embryonic and fetal tissues. It is also expressed in some adult stem/progenitor cell populations, such as newborn vascular endothelial cell. Differentiation between astrocytic tumors and oligodenoglioma tumor is of paramount importance because of different lines of treatment and different prognosis.
\end{abstract}

Design: We performed Nestin immunostaining on paraffin blocks of 16cases of astrocytomas of various grades (3Glioblastoma, 3anaplastic astrocytoma, 3fibrillary astrocytoma and 7Pilocytic astrocytoma) and on 12 oligodendroglioma (6 grade II, and 6 grade III). All cases of oligodendroglioma has confirmation by FISH for 1p 19q.

Result: Nestin staining was seen in all astrocytic tumors. The strongest staining was in glioblastomas and in anaplastic astrocytomas. Pilocytic astrocytomas show mostly focal and weak staining with strong staining of Rosenthal fibers. Grade II astrocytoma shows weak but more intense staining than pilocytic astrocytoma. No Nestin immunostaining was seen in any of the oligodendroglioma tumor cells, but Nestin stained the endothelial cells in oligodendroglioma as a positive internal control.

Conclusion: Nestin is an important immunohistochemical marker in differentiating oligodendroglioma from astrocytic tumors. Nestin, also, is helpful in grading astrocytoma

Keywords: nestin, astrocytoma grading, oligodendroglioma, immunohistochemistry
Volume 5 Issue I - 2017

\author{
Hussam Abu-Farsakh, ' Aseel Sbeih, ${ }^{2}$ Yomna \\ Abu Farsakh, ${ }^{3}$ Ibrahim Sbeih ${ }^{2}$ \\ 'First Medical Lab, Jordan \\ ${ }^{2}$ Neurosurgery center, Ibn Hytham Hospital, Jordan \\ ${ }^{3}$ Resident at Ibn Haytham Hospital, Jordan
}

Correspondence: Hussam AbuFarsakh, First Medical Lab, Jordan, Email Fllab@yahoo.com

Received: July 24, 2017 | Published: August 18, 2017
Abbreviations: IF, intermediate filament; GFAP, glial fibrillary acidic protein; CNS, central nervous system; GBM, glioblastomas multiforme

\section{Introduction}

Nestin is an intermediate filament (IF) protein. These intermediate filament proteins are expressed mostly in neural stem cells. ${ }^{1-3}$ Nestin is also expressed by many other stem cells and it is considered a primitive marker. ${ }^{4-7}$ Upon differentiation, Nestin becomes downregulated and is replaced by tissue-specific intermediate filament proteins. ${ }^{8}$ During neuro- and gliogenesis, Nestin is replaced by cell type-specific intermediate filaments, e.g. neurofilaments and glial fibrillary acidic protein (GFAP). ${ }^{9}$ One instance of Nestin expression in adult organisms, and perhaps that for which Nestin is best known, are the neuronal precursor cells of the subventricular zone., ${ }^{8,10}$ Interestingly, Nestin expression is reinduced in the adult during pathological situations, such as the formation of the glial scar after CNS injury and during regeneration of injured muscle tissue. ${ }^{11}$ Nestin expression has been extensively used as a marker for central nervous system (CNS) progenitor cells in different contexts. ${ }^{4}$ Nestin has recently received attention as a marker for detecting newly formed endothelial cells. ${ }^{3,12}$

\section{Material and methods}

We performed Nestin Immunostaining on paraffin blocks of 16 cases of astrocytomas of various grades (3Glioblastoma, 3 anaplastic astrocytoma, 3fibrillary astrocytoma and 7Pilocytic astrocytoma) and on 12oligodendroglioma (6 grade II, and 6 grade III) (Table 1). All cases of oligodendroglioma has confirmation by FISH for 1p 19q. In immunohistochemical staining, deparaffinized sections underwent heat induced antigen retrieval [autoclaved in $10-\mathrm{mM}$ citrate buffer $(\mathrm{pH}$ 6.0) for $10 \mathrm{~min}]$ and were subjected to a reaction with $3 \%$ hydrogen peroxidase for $10 \mathrm{~min}$ to remove endogenous peroxidase. Then, the reaction was conducted using a 250-fold diluted solution of rabbit polycolonal anti-human nestin antibody (Biocare concentrated polyclonal antibody dilution 1:250, rabbit polyclonal).

Table I This shows the grades of astrocytoma

\begin{tabular}{|c|c|c|c|c|c|c|}
\hline & $\begin{array}{l}\text { Grade I } \\
\text { Pilocytic } \\
\text { Astrocytoma }\end{array}$ & $\begin{array}{l}\text { Grade II } \\
\text { fibrillary } \\
\text { astrocytoma }\end{array}$ & $\begin{array}{l}\text { Grade III } \\
\text { Anaplastic } \\
\text { astrocytoma }\end{array}$ & $\begin{array}{l}\text { Grade IV } \\
\text { Glioblastoma } \\
\text { multiforme }\end{array}$ & $\begin{array}{l}\text { Grade II } \\
\text { Oligodendroglioma }\end{array}$ & $\begin{array}{l}\text { Grade III Anaplastic } \\
\text { oligodendroglioma }\end{array}$ \\
\hline $\begin{array}{l}\text { No. of } \\
\text { cases }\end{array}$ & 7 & 3 & 3 & 3 & 6 & 6 \\
\hline Gender & $\mathrm{M} 4, \mathrm{~F}: 3$ & $\mathrm{M}: 1, \mathrm{~F}: 2$ & M:2; F:1 & $\mathrm{M}: 2, \mathrm{~F}: 1$ & $\mathrm{M}: 3, \mathrm{~F}: 3$ & $\mathrm{M}: 4, \mathrm{~F}: 2$ \\
\hline $\begin{array}{l}\text { Average } \\
\text { Age }\end{array}$ & 11 & 35 & 44 & 52 & 42 & 46 \\
\hline $\begin{array}{l}\text { Nestin } \\
\text { expression }\end{array}$ & $\begin{array}{l}\text { Negative-very } \\
\text { weak }\end{array}$ & weak & strong & Very strong & negative & Negative \\
\hline
\end{tabular}




\section{Results}

No Nestin immunostaining was seen in any of the oligodendroglioma tumor cells, but Nestin stained the endothelial cells in oligodendroglioma as a positive internal control (Figure 1, Figure 2).

Nestin staining was seen in all astrocytic tumors. Pilocytic astrocytomas show mostly focal and weak staining with strong staining of Rosenthal fibers (Figure 3). Grade II astrocytoma shows weak but more intense staining than pilocytic astrocytoma (Figure 4). The strongest staining was in glioblastomas multiforme (GBM) and in Anaplastic astrocytomas (Figure 5, Figure 6).

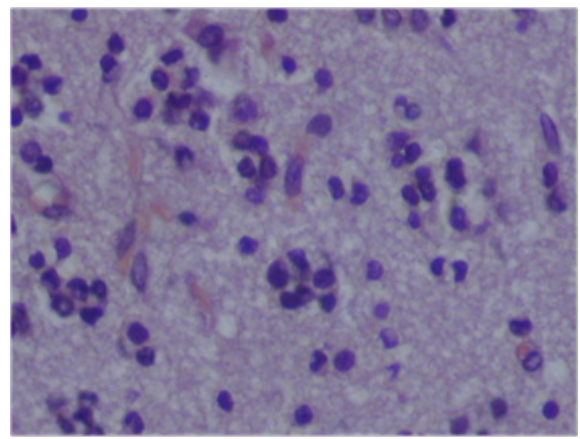

\section{A}

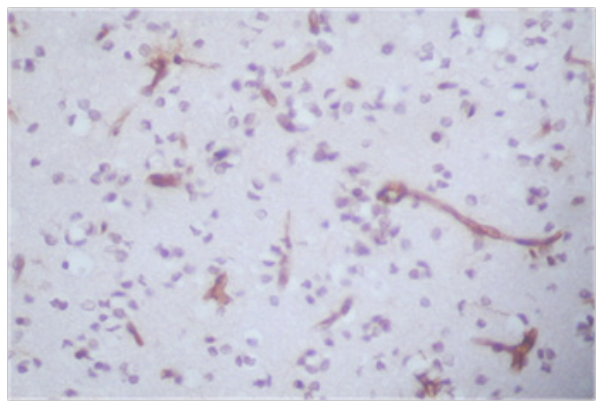

B

Figure I

A: Oligodendroglioma grade II.

B: Negative nestin immunostaining (note positive endothelial staining).

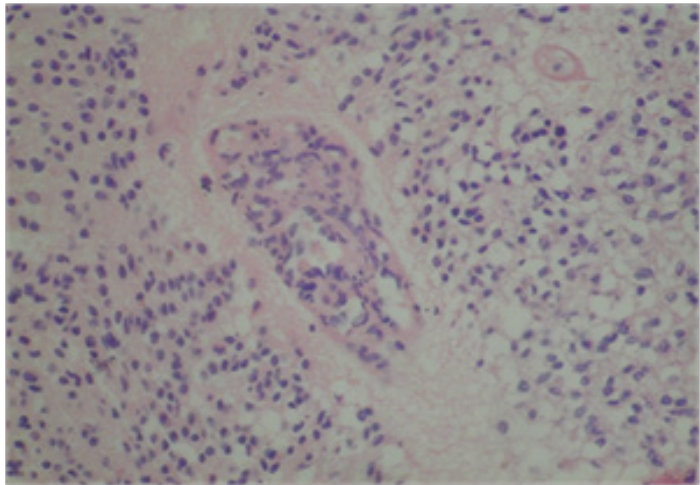

A

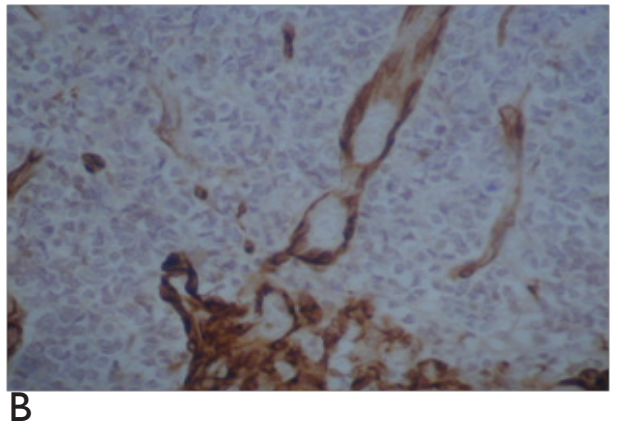

Figure 2

A:Anaplastic oligodendroglioma Grade III.

B: Negative immunostaining for nest in (note positive internal control staining in endothelial cells).

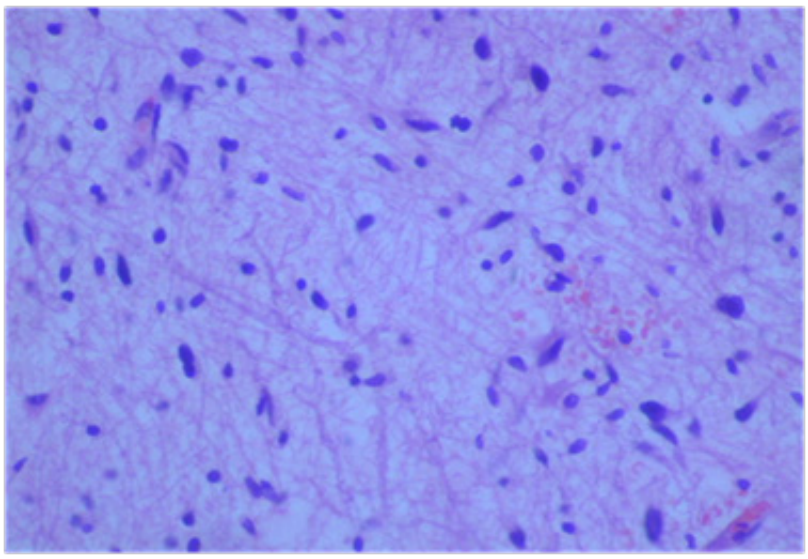

A

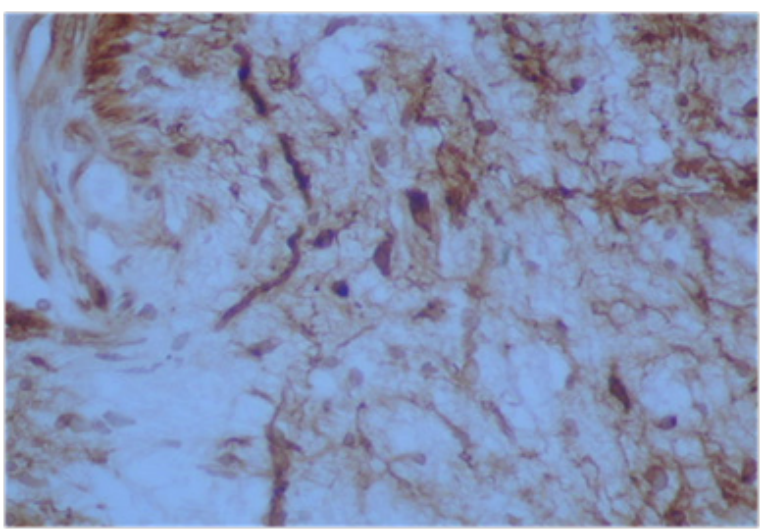

B

Figure 3

A: Pilocystic astrocytoma.

B: Negative-weak staining in the astrocytes, but strong staining in Rosenthal fibers and eosinophilic. 


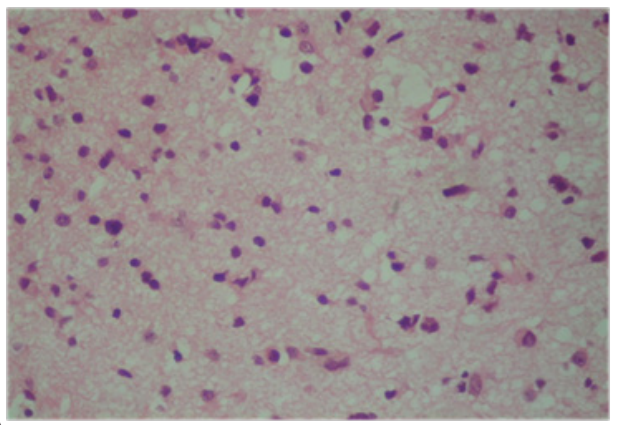

A

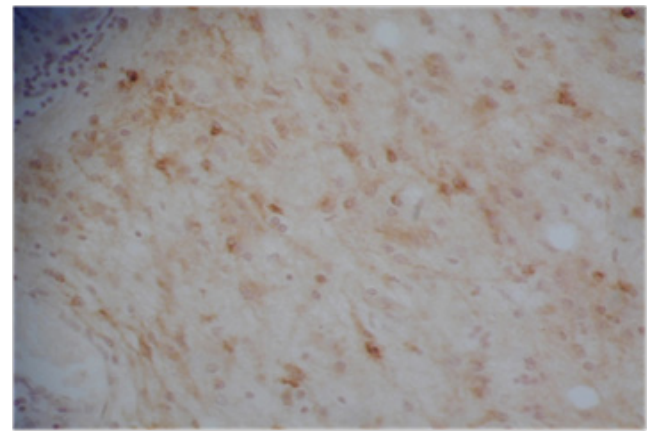

B

Figure 4

A: Low grade astrocytoma.

B:Weak staining in astrocytes.

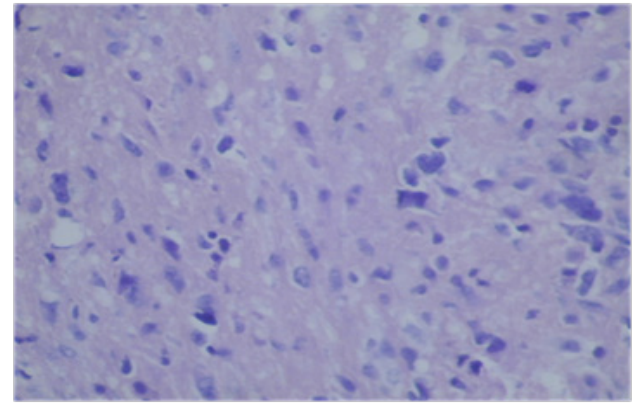

A

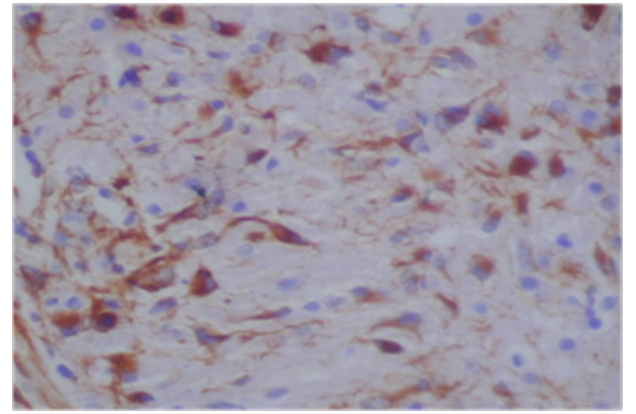

B

Figure 5

A:Anaplastic astrocytoma, Grade III.

B: Strong Immunostaining for Nestin.

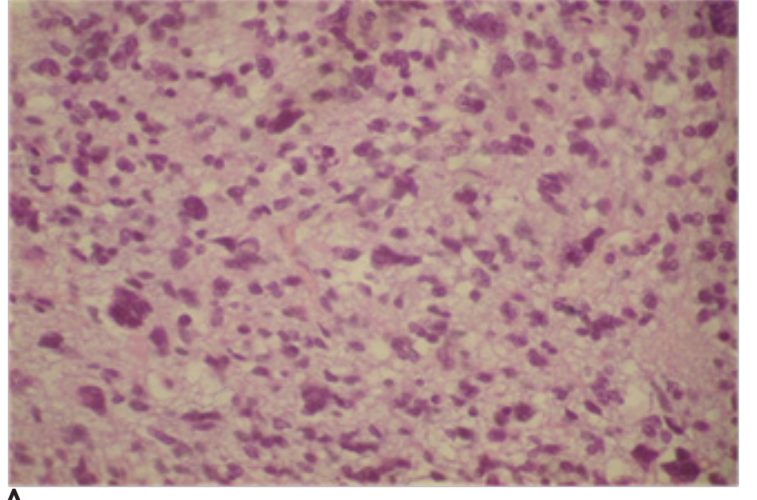

A

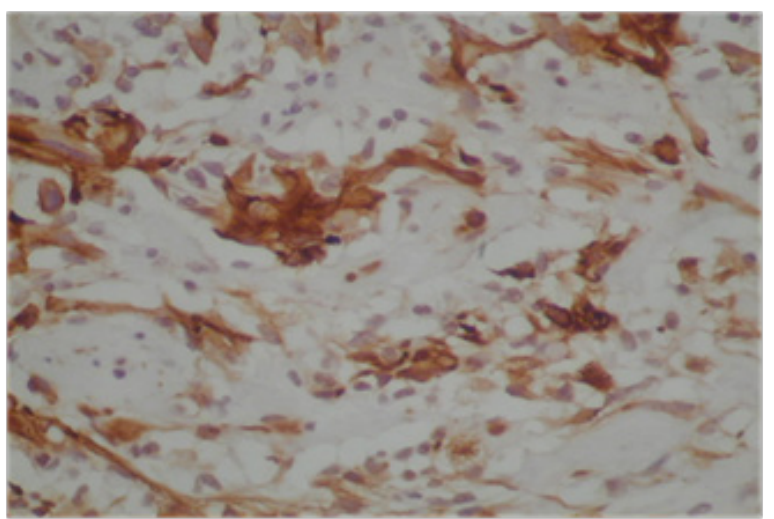

B

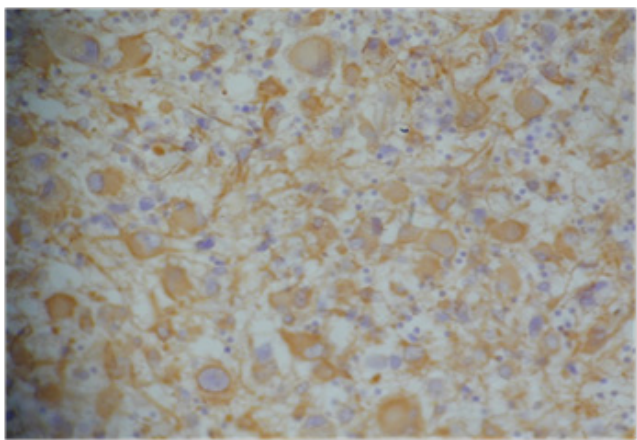

C

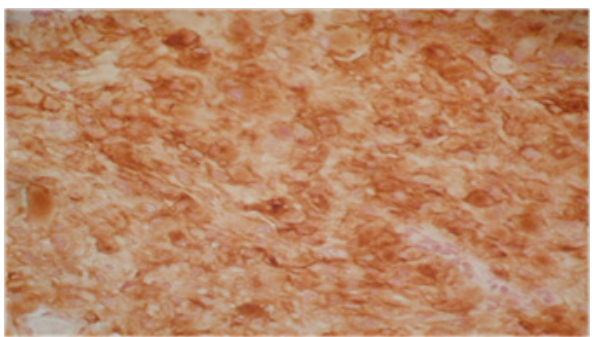

D

Figure 6

A: Glioblastoma multiforme.

$B-D$ : very strong staining for nestin.

Citation: Abu-Farsakh H, Sbeih A, Farsakh YA, et al. Nestin, an important marker for differentiating oligodendroglioma from astrocytic tumors. Int Clin Pathol J. 20I7;5(I):I87-190. DOI: 10.15406/icpil.2017.05.00I20 


\section{Discussion and conclusion}

This study has clarified that the importance of nestin overexpression in glial tumor in two parts: The first one, in helping grading astrocytomas from Grade I-IV. The second part in helping differentiating astrocytomas from oligodendroglioma.

Since Nestin is an important protein in immature neural crest cells, its presence indicate that the cells are of neural crest origin. ${ }^{1-3}$ Brain tumor that originate from neural crest and high grade tumors are expected to over express nestin.

Differentiating astrocytomas into different grades depends on morphology, mitotic figures and Ki-67. For example, differentiating grade II from anaplastic astrocytoma relies on finding mitotic figures 8 . and on Ki-67. Immunohistochemistry for Ki-67 has shown that a very good correlation with glioma grading and behavior. ${ }^{13,14} \mathrm{Ki}-67$ is usually less than $4 \%$ in diffuse astrocytoma grade II. ${ }^{13} \mathrm{Ki}-67$ is a proliferation factor that is expressed in cells in cell cycle during G1, $\mathrm{S}, \mathrm{G} 2 / \mathrm{M}$ phase. ${ }^{9}$ Nestin is expressed in glioma tissue in astrocytoma lineage cells. The degree of nestin expression increases as the degree of malignancy increases, that is, as differentiation decreases. Now with nestin over-expression, we have another objective marker helping us to differentiate and grade astrocytomas. The higher grades of astrocytomas: Glioblastoma multiform and anaplastic astrocytoma, shows strong expression of Nestin (Figures 5 \& Figure 6). ${ }^{4,6,11,15-18}$

Differentiating oligodendrogliomas from astrocytomas is very important because of two main reasons. The first one is that the prognosis of oligodendroglioma is better than astrocytoma, grade for grade. For example Oligodendroglioma grade II, has a median survival of $11.6 y e a r s$ with 10 -year survival rate of $51 \% .^{14,18}$ While the mean survival for fibrillary astrocytoma WHO grade II, is in the range of 6-8 years. ${ }^{18,19}$ The same thing is applied for anaplastic oligodendroglioma grade II with a mean survival of $4-5$, while it is of 2year duration in anaplastic astrocytoma. ${ }^{18}$ Nestin is an important immunohistochemical marker in differentiating oligodendroglioma from astrocytic tumors. ${ }^{411,20,21}$ In oligodendroglioma tumors, nestin was expressed only in tumors with some components of astrocytoma. Nestin is not expressed at all in any of the pure oligodendroglioma cases and only expressed in the vascular endothelium.

\section{Acknowledgements}

None.

\section{Conflict of interest}

The author declares no conflict of interest.

\section{References}

1. Sanai N, Alvarez-Buylla A, Berger MS. Neural stem cells and origin of gliomas. N Engl J Med. 2005;353(8):811-822.

2. Sugawara K, Kurihara $\mathrm{H}$, Negishi $\mathrm{M}$, et al. Nestin as a marker for proliferative endothelium in gliomas. Lab Invest. 2002;82(3):345-351.

3. Tohyama T, Lee VMY, Rorke LB, et al. Monoclonal antibodies to a rat nestin fusion protein recognize a $220-\mathrm{kDa}$ polypeptide in subsets of 2 fetal and adult human central nervous system neurons and in primitive neuroectodermal tumor cells. Am J Pathol. 1993;143(1):258-268.
4. Strojnik T, Rosland GV, Sakariassen PO, et al. Neural stem cell markers, nestin and musashi proteins, in the progression of human glioma: correlation of nestin with prognosis of patient survival. Surg Neurol. 2007;68(2):133-143.

Tohyama T, Lee VMY, Rorke LB, et al. Nestin expression in embryonic human neuroepithelium and in human neuroepithelial tumor cells. Lab Invest. 1992;66(3):303-313.

6. Almqvist PM, Mah R, Lendahl U, et al. Immunohistochemical detection of nestin in pediatric brain tumors. J Histochem Cytochem. 2002;50(2):147158.

7. Maderna E, Salmaggi A, Calatozzolo C, et al. PDGFRbeta, CXCL12 and VEGF in glioma patients. Different profiles of (pro-angiogenic) molecule expression are related with tumor grade and may provide prognostic information. Cancer Biol Ther. 2007;6(7):1018-1024.

Jafri NF, Clarke JL, Weinberg V, et al. Relationship of glioblastoma multiforme to the subventricular zone is associated with survival. Neurol Oncol. 2013;15(1):91-96.

9. Singh K, Hawkins C, Clarke ID, et al. Identification of human brain tumour initiating cells. Nature. 2004;432(7015):396-401.

10. Kappadakunnel M, Eskin A, Dong J, et al. Stem cell associated gene expression in glioblastoma multiforme: relationship to survival and the subventricular zone. J Neurooncol. 2010;96(3):359-367.

11. Arai $\mathrm{H}$, Ikota $\mathrm{H}$, Sugawara $\mathrm{K}$, et al. Nestin expression in brain tumors: its utility for pathological diagnosis and correlation with the prognosis of high-grade gliomas. Brain Tumor Pathol. 2012;29(3):160-167.

12. Chinnaiyan P, Wang M, Rojiani AM, et al. The prognostic value of nestin expression in newly diagnosed glioblastoma. Report from the radiation therapy oncology group. Radiat Oncol. 2008;3:32.

13. McKeever PE, Ross DA, Strawderman MS, et al. A Comparison of the predictive power for survival in gliomas provided by MIB1 , bromodeoxyuridine and proliferating cell nuclear antigen with histopathologic and clinical parameters. J Neuropathol Exp Neurol. 1997;56(7):798-805.

14. Louis DN, Ohgaki H, Wiestler OD, et al. The 2007WHO classification of tumors of the central nervous system. Acta Neuropathol. 2007;114(2):97109.

15. Lim DA, Cha S, Mayo MC, et al. Relationship of glioblastoma multiforme to neural stem cell origins predicts invasive and multifocal tumor phenotype. Neurol Oncol. 2007;9(4):424-429.

16. Ishiwata T, Teduka K, Yamamoto T, et al. Neuroepithelial stem cell marker nestin regulates the migration, invasion and growth of human gliomas. Oncol Rep. 2011;2(1):91-99.

17. Tomita T, Akimoto J, Haraoka J, et al. linicopathological significance of expression of nestin, a neural stem/progenitor cell marker, in human glioma tissue. Brain Tumor Pathol. 2014;31(3):162-171.

18. Ohgaki H, kelihues P. Population based studies on incidence, survival rates and genetic alteration in astrocytic and oligodendroglial gliomas. $H$ Neuopathol Exp Neurol. 2005;64(6):479-489.

19. Ohgaki H, Dessen P, Jourde B, et al. Genetic pathways to a Glioblastoma. A population based study. Cancer Res. 2004;64(19):6892-6899.

20. Kitai R, Horita R, Sato K, et al. Nestin expression in astrocytic tumors delineates tumor infiltration. Brain Tumor Pathol. 2010;27(1):17-21.

1. Schiffer D, Manazza A, Tamagno I. Nestin expression in neuroepithelial tumors. Neurosci Lett. 2006;400(1-2):80-85. 